\title{
Substantiation of the Technology of Efficient Transition to High Bench Stripping of Thick Coal Seams
}

\author{
Viktor Fedotenko ${ }^{1}$, and Ekaterina Esina ${ }^{1, *}$ \\ ${ }^{1}$ Institute of Comprehensive Exploitation of Mineral Resources Russian Academy of Sciences \\ (IPKON RAS), 111020, Moscow, 4, Kryukovsky tupik, Russian Federation
}

\begin{abstract}
One of the most promising areas of increasing the open mining efficiency with the methods reducing the negative impact on the environment is the use of high overburden benches, including those on the basis of the stripping system with overburden transport. The use of high overburden benches in the open mining of steep and steeply dipping deposits ensures the growth of the completeness the deposit's reserves mining while simultaneously increasing the safety and efficiency of open mining operations and reducing the surrounding environmental impact. The justification of the parameters and the technology of an effective transition to the high bench stripping of thick coal deposits is performed. It is proved, that the transition to high overburden benches in the period of maximum development of mining operations provides the increase in the volume of additional recoverable mineral resources by $18-23 \%$ corresponding to the increase in the depth of the open pit mine and the period of its operation. At the same time, the length of transport routes and communications is reduced to $15 \%$, as well as the number of transport equipment and the time for the transfer of machinery and equipment.
\end{abstract}

\section{Introduction}

Increasing costs of mining, associated with the deterioration of mining, geological and mine engineering conditions of mined and prospective deposits, require the use of innovative technologies and the improvement of mining efficiency. The development of existing openpit coal mines is characterized by a further deterioration in mining environment associated with the transition of mining operations to deep horizons, the increase in the stripping ratios, the limited working space of coal mines, as well as the depreciation and the obsolescence of equipment, and the increased damage to the environment. One of the most promising areas for increasing the open mining efficiency is the use of high overburden strips, including those based on the stripping system with overburden transport. In the field of open mining, the potential areas of innovation are improving the methods of opening, mining systems, the formation of open pit area, mining technology and the methods for

${ }^{*}$ Corresponding author: esina555@list.ru 
optimizing their parameters, as well as developmental study of fundamentally new technological and technical solutions [1-3].

\section{The main areas of improving open mining geotechnology using high overburden benches}

The stripping system with overburden transport, which prevails in Russia's open-pit coal mines (it accounts for $68 \%$ of 800 million $\mathrm{m}^{3}$ of the annual volume of overburden), is characterized by a certain conservatism. In particular, for 30-40 years, the height of the bench, the main element of the stripping system with overburden transport, remains within 10-15 m, despite the increase in the depth of open pits by 3-4 times, the excavator bucket capacity - by 5-10 times, and the volume of the mined rock mass - by 4-5 times. One of the ways to significantly improve the technical and economic performance of open-pit mines is the transition to high (up to $30-35 \mathrm{~m}$ and more) bench stripping with the use of new extraction-and-loading equipment.

Since at the layer by layer high bench stripping, the downward scraping excavators (draglines, backhoes), which can also perform (partly) the transportation work by lifting the rock in a bucket, are used in the upper layer, it is necessary to justify the optimum layer height for various equipment complexes according to a minimum of the total operating costs of three interrelated processes - drilling and blasting wells, excavating and loading, transportation of the rock on the pit bank.

It is important to note that earlier, in the project documentation, the insufficient attention was paid to issues of redistribution of stripping volumes and, as a consequence, to a decrease in the current stripping ratio. In justifying the need for reconstructing the open pit edge based on reducing the operating costs, the problem of justifying the feasibility of reconstruction of the open pit from the start to the completion of such a reconstruction as the element of scientific and methodological basis for selecting an open-pit mining strategy remains poorly studied.

It is obvious that the inadequate attention to the solution of this problem is influenced by the adoption of erroneous design solutions, leading to the incorrect determination of the funds sent to production, the overvaluation of the expected benefits and the need for additional, unplanned costs. For the adoption of rational design solutions, it is necessary to carry out a feasibility study of the criterion for optimizing the parameters of mining system at various stages of mining.

In the conditions of the limited production of specialized mining transport equipment that allows high bench stripping according to the stripping system with overburden transport, as well as in the case of the introduction of automated and robotic mining systems, there remains a need to justify the technological schemes of the enterprise as a whole, namely, the development of new horizons, sliding ramp road construction works, high bench stripping [4-13]. These schemes should provide for the use of the existing modern excavation, loading and transport, or robotic intellectual equipment that meets the requirements of economic efficiency of the entire mining and transportation complex of the mining enterprise. Criteria determining the design of the reconstructed open pit shell are the level of the mining equipment operation risk and the costs of its repairs and restoration. Therefore, when determining the height and angle of the slopes and the edges of open pits as a whole, it is necessary to take into account the normative period of their standing, based on the duration of the completion of the contour deposit mining and the additional costs for measures to strengthen high slopes, taking into account the risk of robotic mining equipment operation in high bench stripping conditions.

Known and widely approved methods for the design and operation of open-pit deposits allow, with a certain degree of accuracy, to determine the height of the bench for the 
deposit as a whole, which is usually chosen to be constant for the entire period of the deposit mining. However, the obtained height of the bench does not meet the optimum criterion for the set of all influencing factors. Recently, more powerful and productive mining and transport equipment has appeared. It has been proved by the performed researches that an increase in the height of the bench in the open pit mine will allow solving a number of fundamental problems that are not solvable within the framework of the traditional design methodology. The main advantage of the technology for high bench stripping is the possibility of increasing the inter-ramp angle, reducing the current stripping ratio, reducing the number of transport horizons, etc. The development of robotic geotechnologies for the extraction of minerals from the depths that do not involve the operator in the execution of operational processes in the hazardous mining zone makes it possible to involve into mining the additional reserves of high value mineral raw materials located in dangerous conditions and constraint environment.

Thus, the improvement of open mining geotechnology using high overburden benches is aimed at developing the methods for determining the pit shells and the area of effective application of high overburden benches and taking into account the degree of human participation in the implementation of operational processes, as well as developing methods for determining the parameters of the transition to high bench stripping taking into account the requirements to the value of mineral raw materials, its multicomponent nature, stageby-stage approach to the deposit mining.

\section{Technology of the efficient transition to high bench stripping of thick coal deposits}

The main technological features of high benches include the elevation of the height of the technical parameters of excavator scrapping, and the presence of a continuous single plane of the bench slope before and after mining the current operational block. In addition, blasting of high overburden bench is performed by drilling and blasting deep wells to the full height of the high bench using a relieving wall from the collapsed rock mass, and excavation of the rock from shotpile is carried out in one or two layers using various mining and transport equipment. When stripping a high $(\mathrm{h}=30$ and $32 \mathrm{~m})$ bench in two layers (at the same time), the excavator located in the upper layer must work ahead of the excavator operating in the lower layer. The speed of excavation work in the upper and lower layers along the front of mining operations should be the same [14-15]. Layer by layer high bench stripping according to the stripping system with overburden transport can be realized with the help of various technical means and technological schemes for conducting excavation and loading operations.

The main factors influencing the efficiency of open mining geotechnology using high benches are: the productive strata shape, size and depth, the material composition of minerals, the production capacity of the open pit, the size of the stripping cut, the block, the type of equipment used, the direction and order of mining operations, sequence of mining of individual sections of the deposit, the direction of the subsequent use of the mined out spaces.

The transition to the high bench stripping technology should be carried out step by step. Before the reclamation each stage of the transition is characterized by involvement of an additional horizon into mining operation. The decision to mine an additional horizon is made after checking the fulfillment of two conditions simultaneously: the current stripping ratio is not exceeded and the pit bank stability is maintained.

As physical criteria of the effectiveness of the transition to the high bench stripping technology, the increase in balance mineral reserves in the open pit is considered, as well as 
an additional period of the open pit operability. Among other parameters, the following ones are calculated: the depth of mining at the time of the beginning of the transition to high bench stripping; the inter-ramp angle before and after the transition; the number of horizons that are additionally involved in the mining operation before the reclamation; the increment of the final depth of the open pit; the increment of the open pit boundaries on the top; the duration of the transition to a new technology.

When designing the opening of the deposit, the following points are determined:

- the basic scheme of transportation from the open pit of the established volumes of overburden and minerals;

- schemes of mine workings and transport communications in the dynamics of movement in space and in time as the mining progresses;

- the technology and the organization of the implementation of a set of works to create openings and development workings, transport communications, the formation of the initial mining front, including the calculation of their parameters and the established volume of the discovered reserves, ensuring the implementation of the work schedule.

The opening scheme is determined, first of all, by mining and geological conditions of the deposit occurrence, by the terrain relief, and by the location of reception facilities for placing the rock mass (concentrating mill, dumps, stations, etc.) and other surface structures, as well as the open pit boundaries, stability and parameters of the mining engineering structure of the edges, the deposit mining system, the productivity, the technology used and the type of mining equipment.

For the conditions of mining the flat-lying deposits of the Kuzbass coal basin, a scheme for opening the horizons by high bench stripping method, which provides for the sequence of work on the high overburden bench formation indicated in Figure 1, is proved.

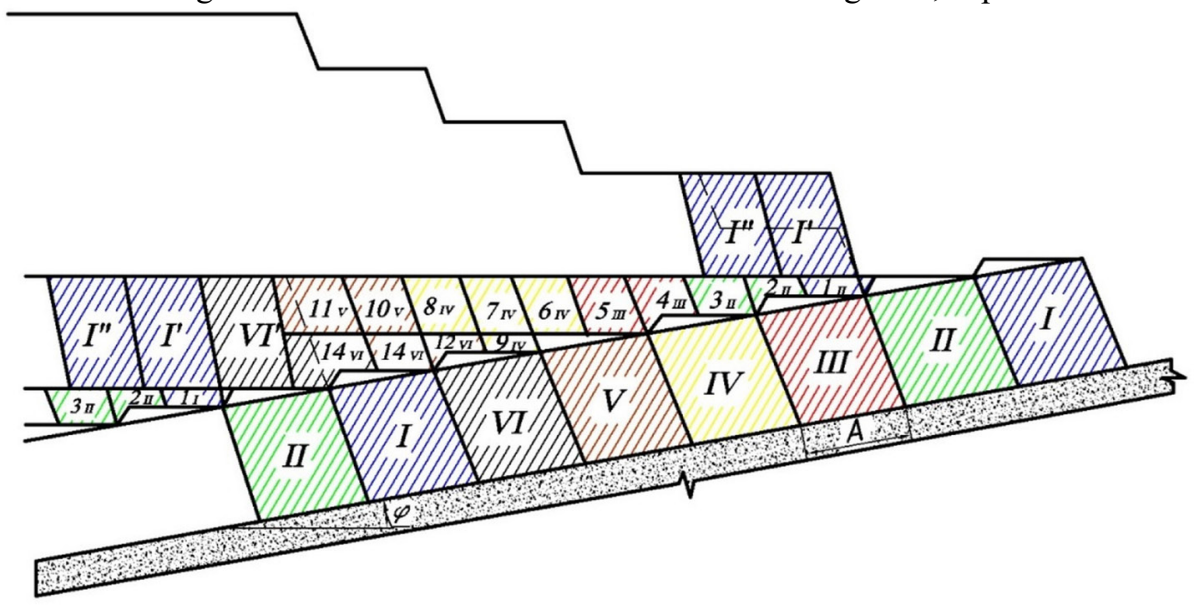

Fig. 1. The order of stripping cuts for the development of new stripping bench in high bench stripping

The overburden rocks on the upper horizons of the open pits at the Kuzbass deposits are mined out using sinker mining system according to the stripping system with overburden transport. The rock is loaded into transport vessels by the face shovel excavators and is transported to external dumps. Overburden, lying directly above the coal layer, is mined using longwall mining system according to the direct dumping method. Excavator-dragline produces excavation of rock from the massif and puts it immediately into the worked-out space, i.e. into the internal dump.

As the mining front advances, a new overburden horizon (bench) appears at the junction of the overburden transport and direct dumping mining systems. For productive and safe 
use of the equipment, a working platform is required for the newly developed rock bench mining. reverse hydraulic shovel

A new horizon (bench) is developed by a back-acting shovel by 14 stripping cuts (stripping cuts $1_{\mathrm{I}}, 2_{\mathrm{II}}, 3_{\mathrm{II}}, 4_{\mathrm{III}}, 5_{\mathrm{III}}, 6_{\mathrm{IV}}, 7_{\mathrm{IV}}, 8_{\mathrm{IV}}, 9_{\mathrm{IV}}, 10_{\mathrm{V}}, 11_{\mathrm{V}}, 12_{\mathrm{V}}, 13_{\mathrm{V}}, 14_{\mathrm{VI}}$ (Figure 1). At the same time in the horizontal bench advance zone directly above the developed horizon, the face shovel must fulfill 10 stripping cuts - I', I", II', II", III', III", IV', IV", V', V". The advance stripping in this zone makes it possible to create the necessary working platform by the beginning of the first stripping cut $1_{I}$ of the developed bench. A new high overburden bench $\left(\mathrm{VI}^{\prime}\right)$ is formed after $14^{\text {th }}$ stripping cut $\left(14_{\mathrm{VI}}\right)$.

The transport inclines of the internal horizon equivalent (sliding ramp roads) are dug for each horizon and are the connecting road-transport link between the bench bottom and the bench top.

Due to the fact that the bench slope angle is much larger than the inclination angle of the sliding ramp road, the latter, i.e. the ramp road, is constructed at a certain angle to the bench edge. For the ramp road construction works it is advisable to use the excavators with a wider range of technological possibilities, namely, downward and upward digging, at or below grade digging, increased linear parameters of the working equipment, and the presence of a device for sight loading of the rock into vehicles.

High benches also have an effect on opening the working horizons by lengthening the ramp road, and the latter requires the selection of the appropriate extraction and loading equipment. Thus, in the transition to stripping $\mathrm{h}=30 \mathrm{~m}$ high benches, the length of sliding ramp road (with a ramp slope of $i=80 \%$ ) doubles from $187.5 \mathrm{~m}$ to $375 \mathrm{~m}$. To construct the ramp road of this length and provided that about $80-90 \%$ of the of the extracted rock volume are removed directly to the dump, a set of two excavators will be needed. For example, the upper part of the ramp road is carried out by crawler dragline EDG-8.55 with loading of soil into BelAZ-7514 installed on pit bank. Subsequent transport of overburden to the dump is then carried out. The lower part of the ramp road is cut by the back digger EX 1900-6 laying the rock on the shotpile slope.

The described technological solutions in high bench stripping take into account the features of cutting a new overburden horizon and determine the sequence of operations for the formation of a high overburden bench.

The optimization of the stripping scheme at the design stage makes it possible to make the proved decisions on the choice of the mining development scheme with different advance rates of overburden benches, which will allow providing the higher reliability and efficiency of open pit operation.

The efficiency of open mining geotechnology is determined by the moment of transition to high bench stripping. The study found that achieving the equality of the current and boundary stripping coefficients $\left(\mathrm{K}_{\mathrm{T}}=\mathrm{K}_{\mathrm{rp}}\right)$ at the full development of mining operations at the open pits occurs at different depths and depends on the rated output and the seam slope angle, the costs of coal mining and the quality of the sold coal products. To determine the changes in the resulting inter-ramp angle depending on the open pit depth and the edge structure, a separate software module was developed. The algorithm for making decisions on the time of transition to high bench stripping with the justification of the conditions for controlling the parameters of the working area is presented in the form of an automated calculation technique that ensures the target character of decision making, which guarantees obtaining results that are close to optimal.

So, if the seam thickness is $20 \mathrm{~m}$, the seam inclination is $40^{\circ}$, the boundary stripping ratio is $10 \mathrm{~m}^{3} / \mathrm{t}$, the transition should start from $120 \mathrm{~m}$; the inter-ramp angle being $\beta=23,5^{\circ}$.That is, to a depth of 120 meters the working zone is formed by the benches with a height of 15 meters. The transition will end at a depth of $180 \mathrm{~m}$, while the inter-ramp angle will reach the value of $\beta=29^{\circ}$. Then you should proceed to the reclamation. With the same 
seam thickness and the inter-ramp angle of $\varphi=40^{\circ}$ but with different amounts of the produced coal (the values $\mathrm{K}_{\mathrm{r}}=\mathrm{K}_{\text {гр }}$ vary from 7 tо 7 до $20 \mathrm{~m}^{3} / \mathrm{t}$ ), it is possible to determine from the graph which inter-ramp angle volume can be reached and when it is necessary to pass to the reclamation (Figure 2).

The executed optimization calculations showed that the transition to high bench stripping in the period of maximum mining operation development provides the increase in the volume of additional recoverable mineral resources by $18-23 \%$, the corresponding increase of the open pit depth and the period of its operation. At the same time, the length of transport routes and communications is reduced to $15 \%$, as well as the number of transport equipment and the time for the transfer of machinery and equipment.

Technological solutions were proposed to reduce the amount of residual worked space, the area and the duration of disturbed land take, and, as a consequence, to reduce the anthropogenic load on the surrounding environment during the large-scale mining of thick overburden deposits.

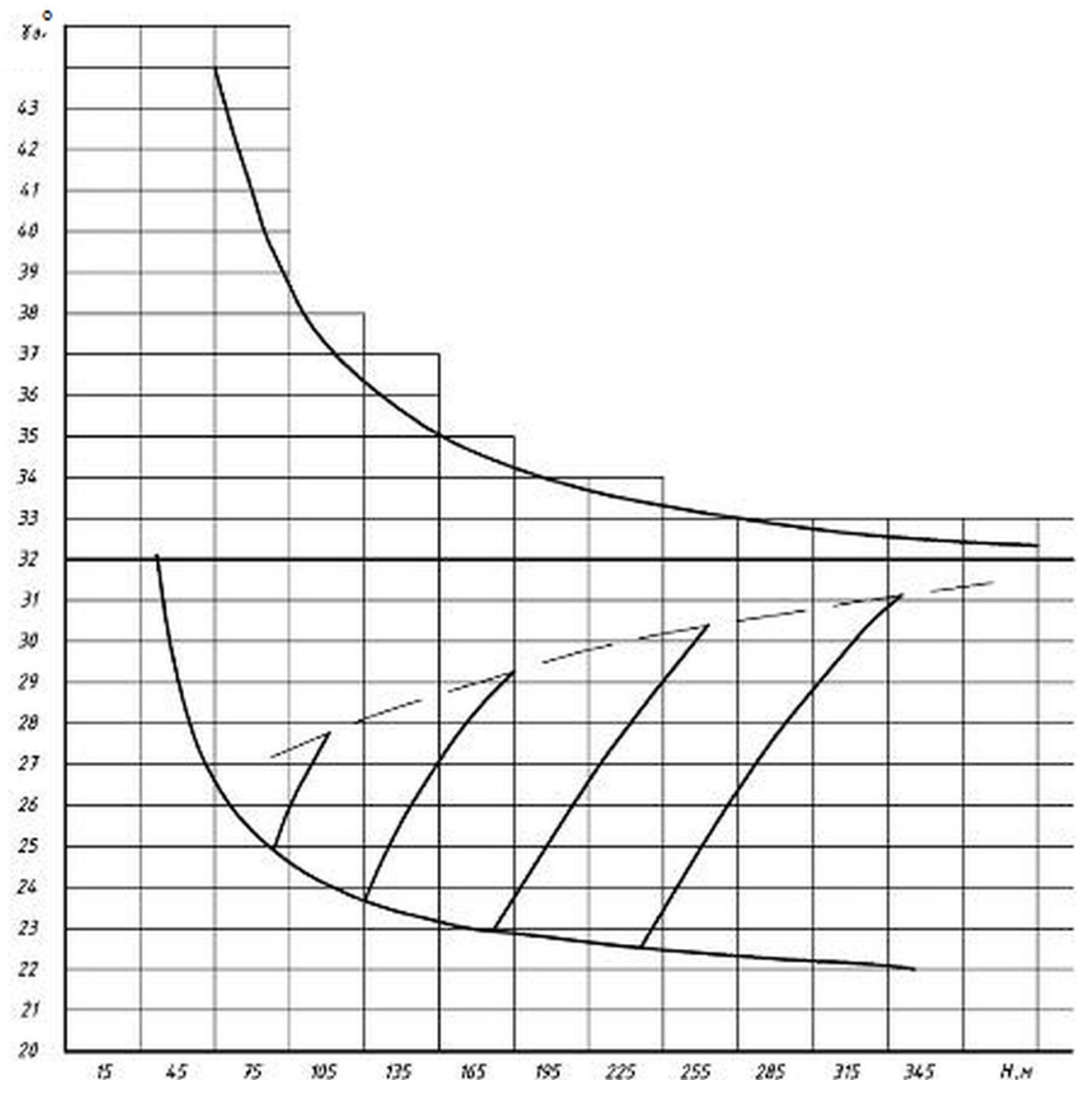

Fig. 2. Change in the inter-ramp angle during the transition to high $(\mathrm{h}=30 \mathrm{~m})$ bench stripping with the seam inclination of $\varphi=40^{\circ}$ and the thickness of the coal seam of $m=20 \mathrm{M}: 1-K_{\mathrm{r}}=\mathrm{K}_{\mathrm{rp}}=7 \mathrm{~m}^{3} / \mathrm{t} ; 2$ $\mathrm{K}_{\mathrm{T}}=\mathrm{K}_{\mathrm{rp}}=10 \mathrm{~m}^{3} / \mathrm{t} ; 3-\mathrm{K}_{\mathrm{T}}=\mathrm{K}_{\mathrm{rp}}=15 \mathrm{~m}^{3} / \mathrm{t} ; 4-\mathrm{K}_{\mathrm{r}}=\mathrm{K}_{\mathrm{rp}}=20 \mathrm{~m}^{3} / \mathrm{t}$. 


\section{Conclusions}

The research has shown that one of the promising areas for increasing the open mining efficiency is the mining of steep and steeply dipping ore and coal deposits with the use of high overburden benches.

It has been proved that the use of high overburden benches in open mining of steep and steeply dipping ensures the increase in the completeness of mining of the deposit's reserves while improving the safety and efficiency of open mining operations and reducing the surrounding environment load.

In general, the transition to high overburden benches in the period of maximum development of mining operations provides the increase in the volume of additional recoverable mineral resources by $18-23 \%$ corresponding to the increase in the depth of the open pit mine and the period of its operation. At the same time, the length of transport routes and communications is reduced to $15 \%$, as well as the number of transport equipment and the time for the transfer of machinery and equipment.

\section{Acknowledgement}

The studies have been performed with the support of the Russian Science Foundation, Project No 14-37-00050

\section{References}

1. K. N. Trubetskoy, D. R. Kaplunov, M. V. Rylnikova, Journal of Mining Science, 48:4, 688 (2012)

2. K. N. Trubetskoy, V. N. Zakharov, D. R. Kaplunov, M.V. Rylnikova, Mining Journal, 5, 34 (2016)

3. S. A. Ilin, V. S. Kovalenko, D. V. Pastikhin, Mining Journal, 2, 37 (2012)

4. K. N. Trubetskoy, Mining journal, 7, 4 (2013)

5. K. Trubetskoy, M. Rylnikova, E. Esina, E3S Web of Conferences, 21, 02008 (2017).

6. M. V. Rylnikova, D. J. Vladimirov, I. A. Pytalev, T. M. Popova, Journal of Mining Science, 53:1, 92 (2017)

7. K. N. Trubetskoy, M. V. Rylnikova, D. J. Vladimirov, I. A. Pytalev, Mining journal, 11, 60 (2017)

8. C. Brown, Autonomous Mining, 1, 30 (2012)

9. S. Arvidsson, Géosciences, 1, 64 (2005)

10. E. Nebot, Robotics Research, 28, 268 (2007)

11. J. J. Green, K. Hlophe, J. Dickens, R. Teleka, M. Price, International Journal of Engineering and Advanced Technology, 1:4, 8 (2012)

12. R. Thompson, S. Hahn, S. Pastor, Mining Engineering, 67:9, 34 (2015)

13. R. Van Berkel, Journal of Cleaner Production, 15, 741 (2007)

14. M. V. Rylnikova, D. Ya. Vladimirov, V S. Fedotenko, E. N. Esina, Mining journal, 1, 32 (2018)

15. V. A. Kovalev, V. S. Fedotenko, Journal of Mining Science, 51:5, 865 (2015) 